\title{
プロセスの動特性を考慮した非線型ソフトセンサー手法の開発
}

\author{
金子弘 昌*・船 津 公 人*
}

\section{Development of Nonlinear Soft Sensor Methods Considering Process Dynamics}

\author{
Hiromasa KANEKO* and Kimito FunATsu*
}

\begin{abstract}
Soft sensors have been widely used for process control in industrial plants to estimate difficult-to-measure process variables online. A genetic algorithm-based process variables and dynamics selection (GAVDS) method is one method used to select important process variables and optimal time-delays of each variable simultaneously. However, the GAVDS method cannot handle a nonlinear relationship between $\mathbf{X}$ and an objective variable $\mathbf{y}$ because linear regression is used as a modeling technique. We therefore proposed a region selection method based on GAVDS and support vector regression (SVR), which is a nonlinear regression method. The proposed method is named GAVDS-SVR. We applied GAVDS-SVR to simulation data having high correlation between close pairs of $\mathbf{X}$-variables and a nonlinear relationship between $\mathbf{X}$ and $\mathbf{y}$. The GAVDS-SVR method could select regions of $\mathbf{X}$-variables appropriately by considering the nonlinearity and could construct predictive models with high accuracy. Through soft-sensor analysis of industrial polymer process data, we confirmed that predictive, easy-to-interpret, and appropriate models were constructed using the proposed method.
\end{abstract}

Key Words: soft sensor, process control, variable selection, time delay, support vector regression

\section{1. 緒言}

化学プラントの安全で安定した運転のためには，プラント の運転状態を監視し, 温度, 圧力, 流量, 濃度などのプロセ ス変数を制御する必要がある。そのため制御したい変数をオ ンラインで測定する必要があるが，必ずしも簡単に測定でき るとは限らない。 その理由として，技術的に困難であること， 分析結果が得られるまでに多くの時間を要すること, 分析機 器の設備費などが高いことが挙げられる。この問題を解決す るため, 化学プラントにおいてはソフトセンサー 1),2)が広く 用いられている.ソフトセンサーとは, オンラインで測定可 能な変数と測定困難な変数の間で数值モデルを構築し，目的 とした変数の值を推定する手法である. Fig. 1 がソフトセン サーの概念図である，ソフトセンサーを用いることで，オン ラインで精度良く目的变数 $\mathbf{y}$ の值を推定できる.

ソフトセンサー推定值を実測值の代替としてプロセス管理 へ応用することにより，迅速な制御を連続で行なうことが可 能となる.さらに, ソフトセンサーに将来の操作変数の值を 入力して出力の将来予測を行なうことで, ソフトセンサーを モデル予測制御へ応用可能である。つまりモデル予測制御に おいて, ソフトセンサーを用いて将来の出力の值を予測し, そ

* 東京大学大学院工学系研究科 東京都文京区本郷 7-3-1

* Department of Chemical System Engineering, The University of Tokyo, 7-3-1 Hongo, Bunkyo-ku, Tokyo

(Received April 19, 2012)

(Revised July 27, 2012)
の予測值が目標值に近づくように操作を決定する．製品品質 の安定化やプラント運転の効率化などを目的として，ソフト センサーを実プラントへ適用することが一般的となっている.

実際のプラントにおいて観測可能な変数（プロセス変数） は時間遅れを伴って $\mathbf{y}$ に影響を与える場合がある. $m$ をモデ ル構築用デー夕数, $n$ をプロセス変数中のソフトセンサーへ 入力される変数 (入力変数) の数, $t_{i}$ を $i$ 番目の入力変数に おける最大の時間遅れとすると, $\mathbf{y} \in R^{m \times 1}$ の線型回帰モデ ルは以下のように表現できる。

$$
\mathbf{y}=\sum_{i=1}^{n} \sum_{j=0}^{t_{i}} b(i, j) \mathbf{x}_{i}(j)+\mathbf{e}
$$

ここで, $\mathbf{x}_{i}(j) \in R^{m \times 1}$ は $\mathbf{y}$ に対してある時間 $j$ だけ過去の $i$ 番目の入力変数, $b(i, j)$ は $\mathbf{x}_{i}(j)$ の回帰係数, $\mathrm{e} \in R^{m \times 1}$ はモデル誤差である. 実際は, 説明変数 $\mathbf{X} \in R^{m \times n\left(t_{i}+1\right)}$ Fig. 2 のような行列の形にして $\mathrm{y}$ との間で回帰を行なう.

一方，ソフトセンサーで扱うプロセスデータにおいては, $\mathrm{X}$ の変数間に強い共線性があり, $\mathrm{y}$ に最も影響度の大きい少 数の変数の組を選択することが望まれている．金子らは時間 遅れ変数はある幅をもって $\mathbf{y}$ と関係がある,つまり(1) 式にお いて $\mathbf{x}_{i}(j)$ が $\mathbf{y} に と っ て$ 重要な変数である場合に $\mathbf{x}_{i}(j-1)$ や $\mathbf{x}_{i}(j+1)$ なども重要であると考え, プロセス変数とその連続 的な時間遅れ变数を同時に選択することを目的として genetic algorithm-based wavelength selection (GAWLS) 法 ${ }^{3)}$ 改良した genetic algorithm-based process variables and dynamics selection (GAVDS) 法を提案した ${ }^{4)}$. GAVDS 法 


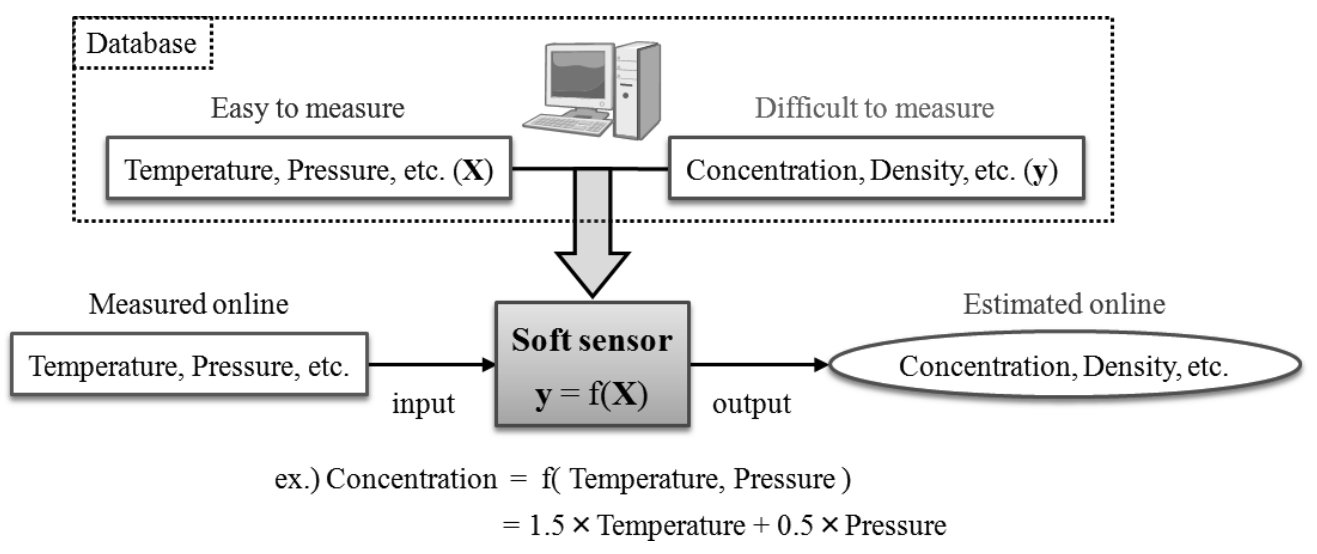

Fig. 1 Basic concept of a soft sensor

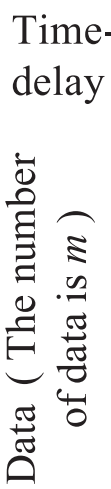

\section{Explanatory variables $\mathbf{X}$}

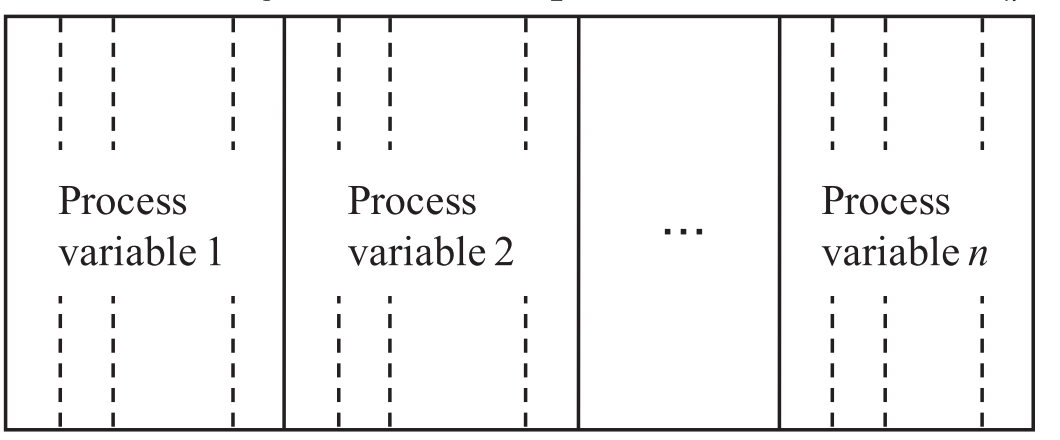

\section{An objective variable $\mathbf{y}$}

Fig. 2 A data representation considering process variables and dynamics. $t_{1}, t_{2}, \ldots, t_{n}$ represent time and $n$ is the number of process variables. The total number of $\mathbf{X}$-variables is $\left(t_{1}+1\right)+\left(t_{2}+1\right)+\cdots+\left(t_{n}+1\right)$
とは，GA を用いてモデルの予測的説明分散 $\left(q^{2}\right)$ の值を大き くする X の变数 (Fig. 2) の組を領域単位で選び出す変数選 択法であり，変数領域とその組み合わせを同時に最適化でき る. $q^{2}$ については付録 $\mathrm{A}$ を参照されたい. 実際の蒸留塔に おける運転データを用いたケーススタディにより, GAVDS 法を用いることで少ないプロセス変数における連続的な時間 遅れ変数のみによりシンプルで理解しやすいソフトセンサー モデルを構築可能であることが確認された ${ }^{4)}$.

しかし, GAVDS 法に拈けるモデル構築手法として線型回 帰分析手法の一つである partial least squares (PLS) 法が使 用されており， $\mathbf{X}$ と $\mathbf{y}$ の間の非線型関係を一つのモデルで表 現することは困難である．このような変数間の非線型性はソ フトセンサー解析においても報告されている5) 7).

そこで本研究では, 変数間に非線型性が存在する場合にお いても適切な変数領域選択と予測精度の高いモデル構築を同 時に達成することを目的として, GAVDS 法と非線型回帰分 析手法の一つである support vector regression (SVR) 法 ${ }^{8)}$ を組み合わせた新規な変数領域選択手法を開発した。この提 案手法を GAVDS-SVR 法と呼ぶ. GAVDS-SVR 法を用い ることで，SVR 法による非線型性の抽出と GAVDS 法によ る領域単位の変数選択が同時に実現できると考えられる。な
お，GAWLS 法と GAVDS 法の関係と同様に, GAWLS 法 を非線型に拡張した GAWLS-SVR 法 ${ }^{9}$ と GAVDS-SVR 法 の概念は同じである。

本手法の有効性を確認するため, 変数間および時間遅れ変 数間の相関の強い $\mathbf{X}$ と $\mathbf{y}$ の間に非線型関係が存在する場合 を想定したシミュレーションデータを用いた解析を行ない, その後実際のプラントデータへ応用する。 それぞれにおいて， PLS 法, GAVDS 法, SVR 法, GAVDS-SVR 法を用いて比 較と検討を行なう。

なお本論文ではデータ形式として, Fig. 2 のようにプロセス 変数ごとに時間遅れが大きくなるにつれて右に变数が並ぶ形 式を使用する．システム同定の分野においてはy の時間遅れ も考慮した autoregressive exogenous (ARX) モデルが広く 用いられている。しかしソフトセンサーでは実測值が得られ るまでに多くの時間がかかり，また不定期にしか測定されな いyを扱う場合が多いため, ARX モデルは適したモデルでは ない. Fig. 2 の形式でモデルが構築されれば，たとえば $\mathbf{y} の$ 分析計故障時など過去の $\mathbf{y}$ の実測值が得られなくても $\mathbf{X} の$ みから $\mathbf{y}$ の值を推定可能である. ただし, Fig. 2 の $\mathbf{X} に \mathbf{y} の$ 時間遅れ変数を追加することで ARX モデルと同等の構造に なる。 


\section{2. 手法}

\subsection{GAVDS 法}

Genetic algorithm (GA) ${ }^{10)}$ とは, 生物の遺伝のようすを 模倣した最適化手法である。 0 と 1 で表現された染色体に対 し, 突然変異や交叉といった操作を行ない, 新たな染色体を作 り出す。そして各染色体について評価值を計算し, 淘汰, 選 択を行なう。これによって, 優れた個体の周辺の空間が優先 的に探索され, 結果として最適に近い解が効率良く発見可能 である。

GAWLS 法は GA を用いて最適な PLS モデルを与える X の 変数の組を領域単位で選び出す変数選択法である. Fig. 3 に GAWLS 法におけるコーディング法を示す．GAWLS 法では 二つの実数值を用いて一つの変数領域を表現することで, モデ ル作成に重要な変数を領域単位で選択することができる．染 色体の評価值は, 染色体に表現された変数領域について PLS 解析を行なった後の $q^{2}$ 值を用いる。これにより, 予測精度の 高いモデルを構築することのできる変数領域の組み合わせが 得られる。

GAWLS 法をプロセスデータに適用できるよう改良した手 法が GAVDS 法である. GAVDS 法においては複数のプロ
セス変数を超えて変数領域が選択されることはない. Fig. 2 のようなデータ形式においては，変数間に互いに強い相関関 係があるため，X のある時間領域が $\mathbf{y} に$ に影響を及ぼすこと は妥当であると考えられる。したがって，モデルがデー夕に 過適合するオーバーフィッティングを起こすことなく，yに とって重要なプロセス変数とその時間遅れを同時に探索で きる。

The first numbers of the selected variables.

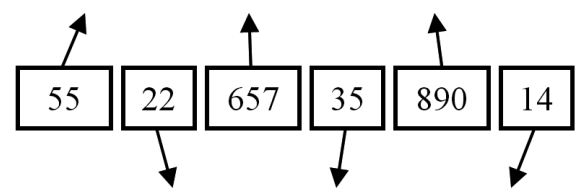

The widths of the selected variables from the left variable numbers.

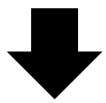

The $\mathbf{X}$-variables whose numbers are 65 through 76 , 657 through 681, and 890 through 903 are selected.

Fig. 3 Coding rule for GAWLS. This is the case that the number of regions is 3

The first numbers of the selected variables.

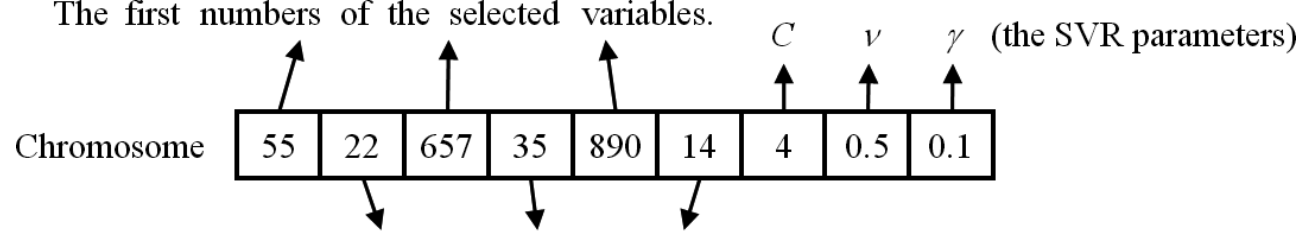

The widths of the selected variables

from the left variable numbers.

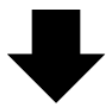

Explanatory variables $\mathrm{X}$

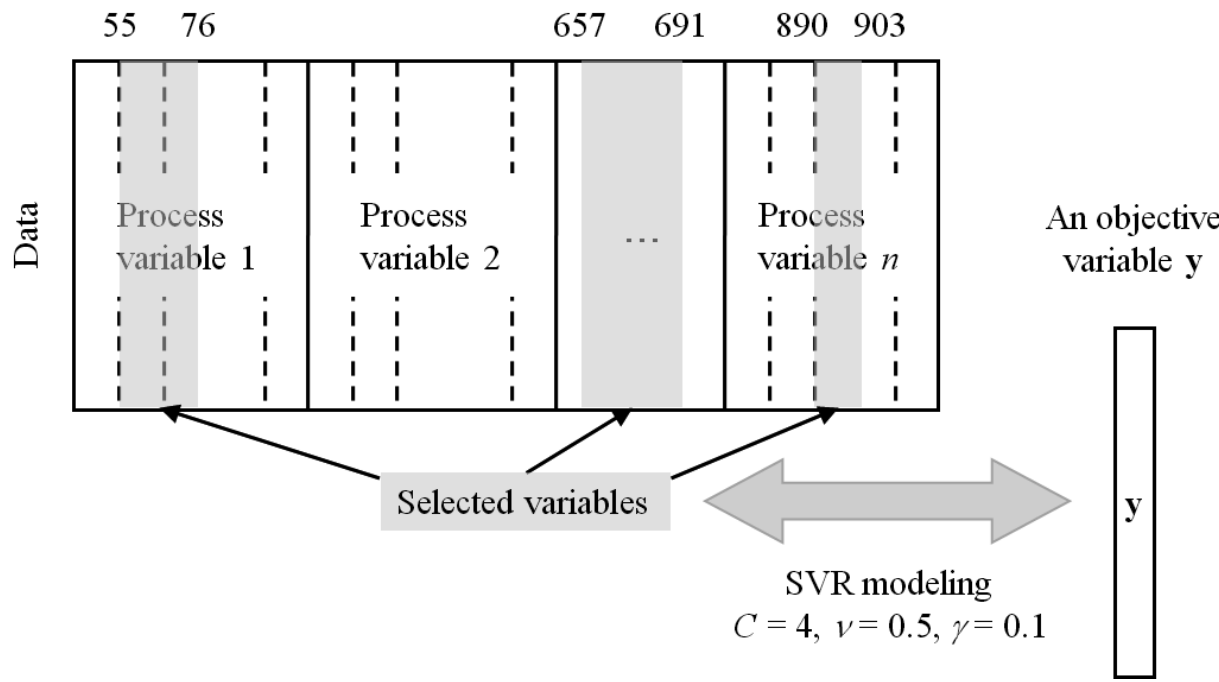

Fig. 4 Basic concept of the GAVDS-SVR method. This is the case that the number of regions is 3 


\subsection{GAVDS-SVR 法}

GAVDS-SVR 法とは, GAVDS 法におけるPLS とした手法である.SVR 法については付録 B を参照された い. 染色体の適合度として, 染色体に表現された変数領域に ついて SVR 解析を行なった後の $q^{2}$ 值を用いることで, 予 測性に優れた非線型モデルを構築できる変数領域の組が得ら れる.

しかし SVR 法においては, モデルを構築するデータ数に 対して指数関数的に計算時間が増加するだけでなく, 最適 化すべきパラメータが $C, \nu, \gamma$ の三つも存在する。そそのた めGAVDS に扔ける PLS 法と同様にクロスバリデーション によりパラメー夕を最適化した後に $q^{2}$ 值を求めると, 多大 な時間がかかってしまう。そこで SVR モデルのパラメータ も GA の染色体に含めることにより計算時間の問題に対応 する.

Fig. 4 に GAVDS-SVR 法の概念図を示す. GAVDS-SVR 法では染色体の前半で変数領域を表現し, 最後の三つの成分で SVR パラメータを表現する。これにより染色体の適合度であ るSVR モデルの $q^{2}$ 值を計算する際に三つのパラメータを最 適化する必要がなく, 計算時間を大幅に短縮可能である. 本 手法を用いることで, $\mathbf{X}$ と $\mathbf{y}$ の変数間に非線型性が内在する 場合においても, 変数領域の組とSVR モデルを同時に最適化 することができる。なお，GAVDS 法と同様に GAVDS-SVR 法においては複数のプロセス変数を超えて変数領域が選択さ れることはない.

\section{3. 結果と考察}

提案手法の有用性を確認するため, シミュレーションデー 夕とあるポリマー重合プラントにおいて実際に測定された データを用いた解析を行なった. PLS 法, GAVDS 法, SVR 法, GAVDS-SVR 法によるモデル構築と予測の結果, そして GAVDS 法と GAVDS-SVR 法の变数選択結果を比較, 検討 した.

\section{1 シミュレーションデータを用いた解析}

プロセスデータにおいては $\mathrm{X}$ の入力变数間および時間遅れ 変数間に相関が強く, ある時間幅をもって入力変数の時間遅 れ変数と $\mathbf{y}$ との間に関係があるといわれている. そこで今回 はそれを模倣してデータを作成した． $\mathbf{X}$ の入力变数の数は 7 であり $(n=7)$, 入力変数は以下の式で表わされる時間変化 をする。

$$
\mathbf{x}\{t+1\}=\mathbf{x}\{t\} \mathbf{G}+0.25 \mathbf{w}\{t\}
$$

ただし, $\mathbf{x}\{t\} \in R^{1 \times 7}$ は時間 $t$ における七つの入力変数のべ クトル, $\mathbf{G} \in R^{7 \times 7}$ は

$$
\mathbf{G}=\left[\begin{array}{ccccccc}
0.5 & 0.45 & 0 & 0 & 0 & 0 & 0 \\
0 & 0.5 & 0.45 & 0 & 0 & 0 & 0 \\
0 & 0 & 0.5 & 0.45 & 0 & 0 & 0 \\
0 & 0 & 0 & 0.5 & 0.45 & 0 & 0 \\
0 & 0 & 0 & 0 & 0.5 & 0.45 & 0 \\
0 & 0 & 0 & 0 & 0 & 0.5 & 0.45 \\
0.45 & 0 & 0 & 0 & 0 & 0 & 0.5
\end{array}\right]
$$

で表わされる行列, $\mathbf{w}\{t\} \in R^{1 \times 7}$ は -1 から 1 までの一様分 布の乱数のべクトルである. $\mathbf{x}\{0\} \in R^{1 \times 7}$ を -5 から 5 まで の一様分布の乱数で初期化し， $t=1,000$ までデー夕を発生 させた. $t$ が 601 から 800 までをモデル構築用データ， $t$ が 801 から 1,000 までのデータをモデル検証用データとした.

(2), (3) 式により，変数番号の近いプロセス変数間掞よび 各プロセス变数における時間遅れが近い変数間の相関は高い. 本論文では時間遅れ变数について $t_{1}=t_{2}=\cdots=t_{7}=20$ としたため, $\mathbf{X}$ の全変数の数は $147(=7 \times 21)$ となった. これは Fig. 2 において $\mathbf{x}_{i}$ ごとに $\mathbf{x}_{i}(0), \mathbf{x}_{i}(1), \ldots, \mathbf{x}_{i}(20) \in$ $R^{1,000 \times 1}$ が横に並ぶことに対応する.

$\mathbf{x}_{i}$ が動特性をもって $\mathbf{y}$ へ寄与することおよび $\mathbf{x}_{i}$ と $\mathbf{y}$ との 非線型性を考慮するため, $\mathbf{y}$ を以下のように設定した.

$$
\mathbf{y}=\sum_{s=0}^{20}\left[\mathbf{x}_{2}(s) c_{2}(s)+\left\{\mathbf{x}_{3}(s)\right\}^{2} c_{3}(s)+\exp \left\{\mathbf{x}_{5}(s)\right\} c_{5}(s)\right]
$$

ここで, $c_{2}(s), c_{3}(s), c_{5}(s)$ はそれぞれ $\mathbf{x}_{2}, \mathbf{x}_{3}, \mathbf{x}_{5}$ が時間 $s$ だけ遅れた変数の重みであり, 以下のように表わされる.

$$
\begin{aligned}
& c_{2}(s)=\frac{1}{2 \pi} \exp \left(-\frac{(s-10)^{2}}{40}\right) \\
& c_{3}(s)=\frac{3}{\pi} \exp \left(-\frac{(s-15)^{2}}{40}\right) \\
& c_{5}(s)=\frac{1}{3 \pi} \exp \left(-\frac{(s-5)^{2}}{60}\right)
\end{aligned}
$$

(4) 式から $\mathbf{x}_{2} ， \mathbf{x}_{3} ， \mathbf{x}_{5}$ のみが $\mathbf{y}$ と関係しており， $\mathbf{x}_{3}$ およ び $\mathrm{x}_{5}$ と $\mathbf{y}$ との間には非線型関係があることがわかる。また (5)，(6)，(7) 式より $\mathbf{x}_{2} ， \mathbf{x}_{3} ， \mathbf{x}_{5}$ はそれぞれ $10 ， 15 ， 5$ だけ 遅れた変数の重みが最大であり, 時間幅をもって $\mathbf{y}$ と関係し ている. 最後に $\mathbf{X}$ と $\mathbf{y}$ に平均 0 , 標準偏差 0.1 の正規分布 の乱数をノイズとして加えた. Table 1, Table 2 にそれぞ れモデル構築用データおよびモデル検証用デー夕の $\mathrm{x}_{1}, \mathrm{x}_{2}$, $\mathrm{x}_{3}, \mathrm{x}_{4}, \mathrm{x}_{5}, \mathrm{x}_{6}, \mathrm{x}_{7}, \mathrm{y}$ の各統計量を示す.

PLS 法, GAVDS 法, SVR 法, GAVDS-SVR 法により モデル構築と予測を行なった結果を Table 3 に示す. root mean squared error (RMSE) などの各統計量については付 録 A を参照されたい. GAVDS とGAVDS-SVR における GA の計算には genetic algorithm optimizing toolbox for MATLAB $5^{11)}$ を用いた。染色体の評価值は 5-fold クロス バリデーションを行なった際の $q^{2}$ 值とした. GA パラメータ 
T.SICE Vol.49 No.2 February 2013

Table 1 Each statistic of $\mathbf{x}_{1}, \mathbf{x}_{2}, \mathbf{x}_{3}, \mathbf{x}_{4}, \mathbf{x}_{5}, \mathbf{x}_{6}, \mathbf{x}_{7}$, and $\mathbf{y}$ for training data

\begin{tabular}{ccccccccc}
\hline & $\mathbf{x}_{1}$ & $\mathbf{x}_{2}$ & $\mathbf{x}_{3}$ & $\mathbf{x}_{4}$, & $\mathbf{x}_{5}$ & $\mathbf{x}_{6}$ & $\mathbf{x}_{7}$ & $\mathbf{y}$ \\
\hline Max & 0.538 & 0.705 & 0.574 & 0.574 & 0.662 & 0.653 & 0.653 & 37.6 \\
Min & -0.755 & -0.755 & -0.767 & -0.707 & -0.707 & -0.829 & -0.829 & 13.4 \\
Average & -0.023 & -0.015 & -0.009 & -0.020 & -0.012 & 0.008 & 0.0003 & 22.2 \\
Standard deviation & 0.272 & 0.277 & 0.259 & 0.261 & 0.272 & 0.276 & 0.280 & 5.63 \\
\hline
\end{tabular}

Table 2 Each statistic of $\mathbf{x}_{1}, \mathbf{x}_{2}, \mathbf{x}_{3}, \mathbf{x}_{4}, \mathbf{x}_{5}, \mathbf{x}_{6}, \mathbf{x}_{7}$, and $\mathbf{y}$ for test data

\begin{tabular}{|c|c|c|c|c|c|c|c|c|}
\hline & $\mathbf{x}_{1}$ & $\mathbf{x}_{2}$ & $\mathbf{x}_{3}$ & $\mathbf{x}_{4}$, & $\mathbf{x}_{5}$ & $\mathbf{x}_{6}$ & $\mathbf{x}_{7}$ & $\mathbf{y}$ \\
\hline $\operatorname{Max}$ & 0.640 & 0.640 & 0.779 & 0.779 & 0.779 & 0.661 & 0.661 & 36.4 \\
\hline Min & -0.679 & -0.679 & -0.678 & -0.678 & -0.678 & -0.668 & -0.668 & 13.6 \\
\hline Average & 0.012 & 0.002 & -0.011 & -0.012 & -0.020 & 0.023 & 0.026 & 21.5 \\
\hline Standard deviation & 0.279 & 0.277 & 0.253 & 0.2584 & 0.246 & 0.260 & 0.261 & 5.05 \\
\hline
\end{tabular}

Table 3 Modeling and prediction results for the simulation data

\begin{tabular}{ccccccc}
\hline & $r^{2}$ & $R M S E$ & $q^{2}$ & $R M S E_{\mathrm{CV}}$ & $r_{\text {pred }}^{2}$ & $R M S E_{\mathrm{P}}$ \\
\hline PLS & 0.727 & 3.25 & 0.463 & 4.56 & -0.248 & 6.05 \\
GAVDS & 0.572 & 4.06 & 0.512 & 4.34 & 0.008 & 5.38 \\
SVR & 0.999 & 0.002 & 0.892 & 2.04 & 0.482 & 3.90 \\
GAVDS-SVR & 0.999 & 0.025 & 0.947 & 1.42 & 0.814 & 2.32 \\
\hline
\end{tabular}

は世代数 1,000 , 染色体数 500 とし, 交叉や突然変異に関し てはデフォルト值を用いた。なお GAVDS と GAVDS-SVR においては領域数を 3 に固定して 30 回のモデル構築と予測 を行ない, 各統計量の平均を Table 3 に載せた.

PLS モデルにおける $r^{2}$ と $q^{2}$ の值がそれぞれ 0.727 と 0.463 であり GAVDS モデルに拈けるそれらの值が 0.572 と 0.512 であることから, GAVDS 法による変数選択を実施した場合で も各統計量は依然として 1 と比較して低い值であることがわ かる.Fig. 5(a) に GAVDS 法を用いた際の各変数の選択さ れた回数を示す.Fig. 2 と同様に，各 $\mathbf{x}_{i}$ について左から順に $\mathbf{x}_{i}(0), \mathbf{x}_{i}(1), \ldots, \mathbf{x}_{i}(20)$ に対応する選択回数である. $\mathbf{y} へ の$ 寄与のある $\mathrm{x}_{2}, \mathrm{x}_{3}, \mathrm{x}_{5}$ の中で $\mathrm{x}_{3}, \mathrm{x}_{5}$ に対応する変数は全 く選択されず， $\mathbf{x}_{6}, \mathbf{x}_{7}$ といった $\mathbf{y}$ と無関係の変数が選択さ れてしまった. GAVDS 法では非線型性を考慮した適切な変 数選択が達成されなかったことを確認した。

SVR 法によるモデリング結果より,$r^{2}$ と $q^{2}$ の值がそれ ぞれ 0.999 と 0.892 であり PLS モデルや GAVDS モデル と比較して精度と予測性の高いモデルが構築されたことがわ かる．X と $\mathbf{y}$ の間の非線型性にある程度対応できたためと 考えられる。ささに提案手法である GAVDS-SVR 法を用い ることで， $q^{2}$ 值が 0.947 となり SVR 法と比較して向上し た. GAVDS-SVR 法を用いた際の各変数の選択された回数 を Fig. 5(b) に示す. $\mathbf{x}_{2}, \mathbf{x}_{3}, \mathrm{x}_{5}$ の時間遅れ变数の選択回数 が大きくほかの変数は選択されなかったことから，X の変換 が線型や単調増加関数のみならず極小值をもつ関数であって も適切に非線型性に対応し変数選択できたことがわかる．提 案手法を用いることで非線型性を考慮に入れた妥当な変数選

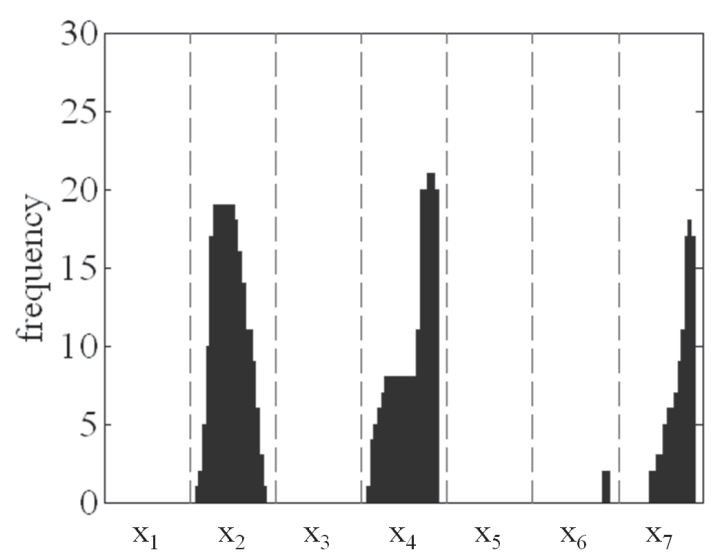

(a) GAVDS

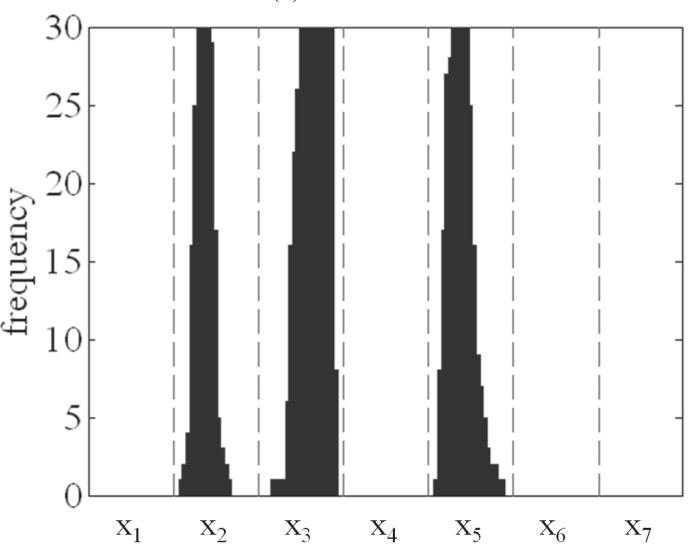

(b) GAVDS-SVR

Fig. 5 Frequency of selection of each variable in the 30 models 
Table 4 Modeling and prediction results for the MFR

\begin{tabular}{cccccccc}
\hline & $\begin{array}{c}\text { Number of } \\
\text { regions }\end{array}$ & $r^{2}$ & $R M S E$ & $q^{2}$ & $R M S E_{\mathrm{CV}}$ & $r_{\text {pred }}{ }^{2}$ & $R M S E_{\mathrm{P}}$ \\
\hline PLS & - & 0.978 & 0.120 & 0.976 & 0.126 & 0.951 & 0.173 \\
GAVDS & 5 & 0.961 & 0.163 & 0.960 & 0.165 & 0.940 & 0.189 \\
GAVDS & 10 & 0.968 & 0.147 & 0.967 & 0.149 & 0.943 & 0.185 \\
GAVDS & 15 & 0.971 & 0.139 & 0.970 & 0.142 & 0.946 & 0.180 \\
SVR & - & 1.000 & 0.016 & 0.990 & 0.082 & 0.958 & 0.159 \\
GAVDS-SVR & 5 & 0.992 & 0.072 & 0.990 & 0.084 & 0.957 & 0.159 \\
GAVDS-SVR & 10 & 0.995 & 0.059 & 0.992 & 0.075 & 0.972 & 0.130 \\
GAVDS-SVR & 15 & 0.996 & 0.055 & 0.992 & 0.072 & 0.968 & 0.137 \\
\hline
\end{tabular}

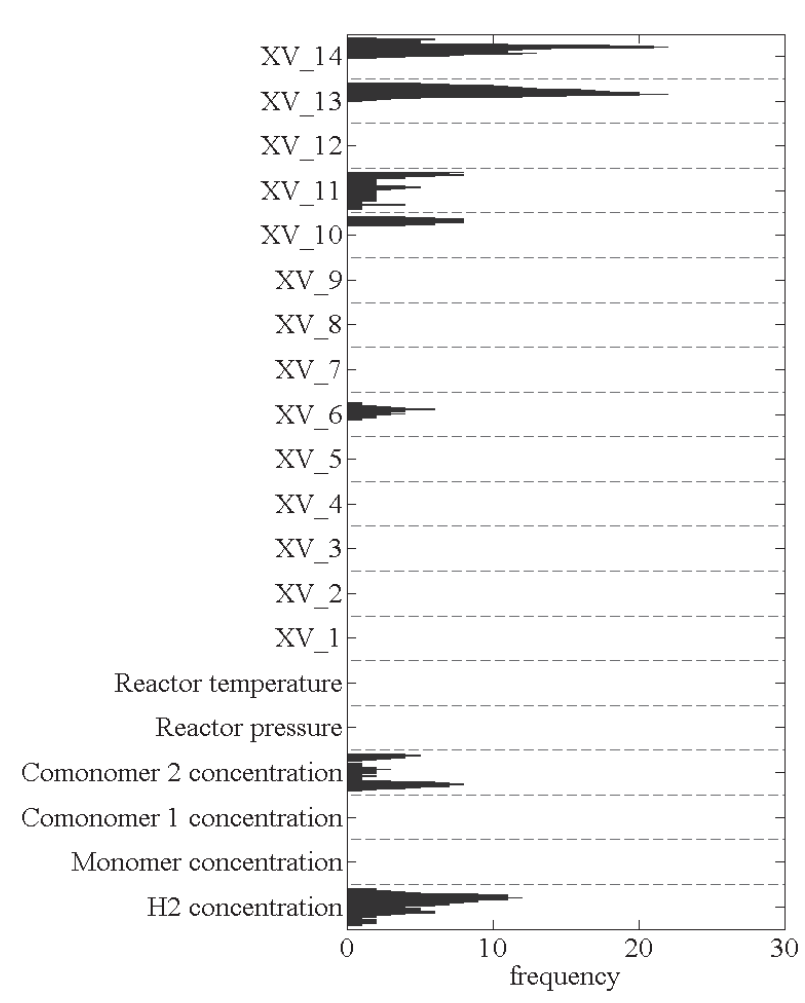

(a) GAVDS

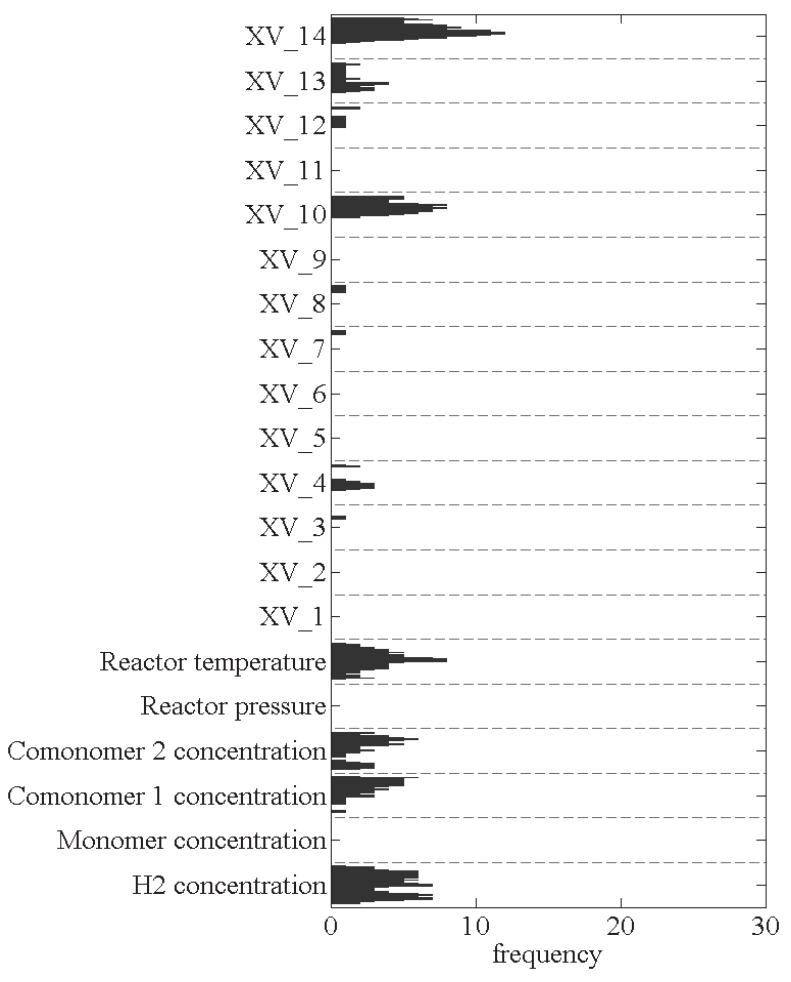

(b) GAVDS-SVR

Fig. 6 Frequency of selection of each variable in the 30 GAVDS-SVR models of the MFR

択が可能であることを確認した。

予測結果を確認すると, 線型手法である PLS 法や GAVDS 法では $r_{\text {pred }}{ }^{2}$ 值がそれぞれ -0.247 と 0.008 であったが, 非 線型手法である SVR 法を用いることで 0.482 に向上した。さ らに提案手法である GAVDS-SVR 法を用いることで 0.814 と最も高い $r_{\text {pred }}{ }^{2}$ 值であり, $R M S E_{\mathrm{P}}$ 值は Table 2 の $\mathrm{y}$ の変 動範囲と比較して小さかった. GAVDS-SVR 法により $\mathbf{X}$ と $\mathbf{y}$ の間に非線型性が存在する場合であっても, 適切な变数選択 と予測性に優れた頑健なモデル構築ができることを確認した.

\section{2 ポリマー重合プラントへの応用}

提案手法の検証を行なうため, 三井化学市原工場のポリマー 重合プラントで実際に測定されたデー夕を用いた解析を行なっ た. 対象としたプロセスにおいては, ポリマー物性とその他
のプロセス変数間の非線型性が原因の一つとなり，予測的な ソフトセンサーモデルの構築は困難となっている.今回は, 2006 年 5 月から 2007 年 4 月に測定されたデー夕をモデル構 築用データ, 2007 年 5 月から 2008 年 5 月に測定されたデー タをモデル検証用データとし, melt flow rate (MFR) を反 応器温度, モノマーおよびコモノマー濃度などの 20 のプロ セス変数から推定するソフトセンサーモデルを構築した。今 回はプロセスの動特性を考慮するため, Fig. 2 のように各プ ロセス変数をある時間まで遅らせた変数を追加して最終的な $\mathbf{X}$ とした。 なお MFR には対数変換を行ない $\mathbf{y}$ とした.

各手法を用いた際の MFR のモデル構築と予測の結果を Table 4 に示す.今回は GAVDS 法および GAVDS-SVR 法について, 領域数を $5,10,15$ と振り検討を行なった。 そ 
れぞれ 30 回のモデル構築と予測を行ない, 各統計量の平均 を Table 4 に記載した。

PLS や GAVDS と比較して SVR や GAVDS-SVR のほう が $r_{\text {pred }}{ }^{2}$ 值が大きく, RMSE $E_{\mathrm{P}}$ 值が小さかった. $\mathrm{X}$ の変数 と MFR の間の関係は非線型であると考えられる. また, 領 域数が 10 または 15 の場合, SVRより GAVDS-SVRのほ うが $r_{\text {pred }}^{2}$ 值が大きく予測精度が向上した. MFRについて は, ある程度モノマーの濃度や温度と MFR の間に相関があ

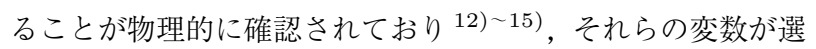
択されることで予測精度が向上したと考えられる。

GAVDS 法およびGAVDS-SVR 法における領域数を 5 と した際の, 各変数の選択回数を Fig. 6 に示す. プロセス変 数ごとに時間遅れが大きくなるにつれて上に変数が並んでい る. 守秘義務契約のためすべてのプロセス変数名が記載され て抢らず，いくつかのプロセス变数は $\mathrm{n}$ をプロセス変数番号 としてXV_nで表現されている．選択された変数を見ると， GAVDS では最もMFR に影響のある変数の一つであるコモ ノマー濃度の一方が選択されなかったのに対し，提案手法を 用いることで両コモノマー濃度が選択された，MFR とコモ ノマー濃度との関係は非線型であるため, GAVDS-SVR 法 により MFR と各コモノマー間の非線型性が抽出できたと考 えられる.

また，MFR と関係の深いと考えられている水素濃度や反

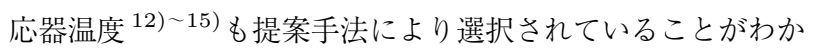
る. 提案手法を用いることで, プロセス変数間の非線型性を 考慮に入れた妥当な変数および動特性の選択，そして予測性 の高いモデル構築が可能になることを確認した. モデルの解 釈および詳細なソフトセンサーモデルの検討が容易であり， メンテナンス負荷の小さいモデルが構築可能であった.

\section{4. 結 言}

本論文では， $\mathbf{X}$ と $\mathbf{y}$ の間に非線型性が存在する場合におい ても適切なプロセス変数の選択および動特性の選択を行なう ことを目的として, GAVDS 法と SVR 法を組み合わせた新 規な変数領域選択手法を提案した。 GAVDS 法における評価 值を SVR モデルの $q^{2}$ 值とすることで, 変数間の非線型性の 考慮と領域単位の変数選択が同時に可能となる.

シミュレーションデータを用いた解析の結果, $\mathrm{X}$ と $\mathrm{y}$ の間に 非線型性が存在する場合は GAVDS 法では対応できないこと を確認した。このような場合に提案手法である GAVDS-SVR 法を用いることで, 非線型性を考慮した適切な変数選択が達 成され精度と予測性能の高いモデルが構築可能であった。

その後, ソフトセンサー解析に提案手法を応用した，提案手 法を用いることで, 他の手法と比較して予測精度の高いモデル 構築が可能であった. プロセス変数間の非線型性と動特性を 適切に考慮して変数領域を選択したためであると考えられる.

本手法により少数の $\mathrm{X}$ の変数のみでモデリングが行なわれ ることで, 高い予測性能と解釈のしやすさを併せもつ実用的 なモデルを得ることができると考えられる。
謝辞 デー夕提供の面で多大なご支援をいただいた三井化 学株式会社に深く感謝致します。

\section{参 考 文 献}

1) M. Kano and Y. Nakagawa: Data-Based Process Monitoring, Process Control, and Quality Improvement: Recent Developments and Applications in Steel Industry, Comput. Chem. Eng., 32-1,2, 12/24 (2008)

2) P. Kadlec, B. Gabrys and S. Strandt: Data-driven Soft Sensors in the Process Industry, Comput. Chem. Eng., 33-4, 795/814 (2009)

3) M. Arakawa, Y. Yamashita and K. Funatsu: Genetic Algorithm-based Wavelength Selection Method for Spectral Calibration, J. Chemom., 25-1, 10/19 (2011)

4) H. Kaneko and K. Funatsu: A New Process Variable and Dynamics Selection Method Based on Genetic Algorithmbased Wavelength Selection Method, AIChE J., 58-6, 1829/1840 (2012)

5) W. Yan, H. Shao and X. Wang: Soft Sensing Modeling Based on Support Vector Machine and Bayesian Model Selection, Comput. Chem. Eng., 28-8, 1489/1498 (2004)

6) H. Kaneko and K. Funatsu: Development of Soft Sensor Models Based on Time Difference of Process Variables with Accounting for Nonlinear Relationship, Ind. Eng. Chem. Res., 50-18, 10643/10651 (2011)

7) P. Kadlec and B. Gabrys: Local Learning-Based Adaptive Soft Sensor for Catalyst Activation Prediction, AIChE J., 57-5, 1288/1301 (2011)

8) C.M. Bishop: Pattern Recognition and Machine Learning, Springer, New York, USA (2006)

9）金子, 船津 : Genetic Algorithm-based WaveLength Selection と Support Vector Regression を組み合わせた変数領域 選択手法の開発，J. Comput. Chem. Jpn., 10-4，122/130 (2011)

10) D. Whitley: A Genetic algorithm tutorial, Statistic and Computing, 4-2, 65/85 (1994)

11) C.R. Houck, J.A. Joines and M.G. Kay: A Genetic Algorithm for Function Optimization: A Matlab Implementation, Technical Report, NCSU-IE TR 95-09, Meta-heuristic Research and Applications Group, North Carolina State University (1995)

12) K.B. McAuley and J.F. MacGregor: On-Line Inference of Polymer Properties in an Industrial Polyethylene Reactor, AIChE J., 37-6, 825/835 (1991)

13) M. Ohshima and M. Tanigaki: Quality Control of Polymer Production Processes, J. Process Control, 10-2-3, 135/148 (2000)

14) E.H. Lee, T.Y. Kim and Y.K. Yeo: Prediction of the Melt Index in a High-density Polyethylene Process, J. Chem. Eng. Japan, 40-10, 840/846 (2007)

15) S.J. Oh, J. Lee and S. Park: Prediction of Pellet Properties for an Industrial Bimodal High-density Polyethylene Process with Ziegler-Natta Catalysts, Ind. Eng. Chem. Res., 44-1, 8/20 (2005)

《付

録》

\section{A. 各種統計量}

回帰モデルの精度, 予測能力の指標として, 本論文では $r^{2}$ 值, $q^{2}$ 值, $R M S E$ 值, $R M S E_{\mathrm{CV}}$ 值を用いた。それぞれ以下のよ うに定義される. 


$$
\begin{aligned}
& r^{2}=1-\frac{\sum\left(y_{\mathrm{obs}}-y_{\mathrm{calc}}\right)^{2}}{\sum\left(y_{\mathrm{obs}}-\bar{y}\right)^{2}} \\
& q^{2}=1-\frac{\sum\left(y_{\mathrm{obs}}-y_{\mathrm{pred}}\right)^{2}}{\sum\left(y_{\mathrm{obs}}-\bar{y}\right)^{2}} \\
& R M S E=\sqrt{\frac{\sum\left(y_{\mathrm{obs}}-y_{\mathrm{calc}}\right)^{2}}{n}} \\
& R M S E_{\mathrm{CV}}=\sqrt{\frac{\sum\left(y_{\mathrm{obs}}-y_{\mathrm{pred}}\right)^{2}}{n}}
\end{aligned}
$$

ここで, $y_{\mathrm{obs}}$ は $\mathbf{y}$ の実測值, $y_{\text {calc }}$ は $\mathbf{y}$ の計算值, $y_{\text {pred }}$ は leave-one-out 法によるクロスバリデーションや N-fold クロ スバリデーションを行なった際の $\mathrm{y}$ の予測值, $n$ はデータ数 を表わす， $r^{2}$ 值が 1 に近いほど，RMSE 值が 0 に近いほど モデルの精度は高く, $q^{2}$ 值が 1 に近いほど, $R M S E_{\mathrm{CV}}$ 值が 0 に近いほどモデルの予測能力は高い.

回帰モデルの外部デー夕に対する予測性の指標として, $r_{\mathrm{pred}}{ }^{2}$ 值と $R M S E_{\mathrm{P}}$ 值を用いた. $r_{\mathrm{pred}}^{2}$ 值はモデル検証用データを 用いた際の $r^{2}$ 值であり, $R M S E_{\mathrm{P}}$ 值は $r_{\mathrm{pred}}{ }^{2}$ に対応する $R M S E$ 值である. $r_{\text {pred }}^{2}$ 值が 1 に近いほど, $R M S E_{\mathrm{P}}$ 值が 0 に近いほど外部データに対するモデルの予測性は高い.

\section{B. SVR 法}

SVR 法は support vector machine $(\mathrm{SVM})^{8)}$ を回帰分析 へ応用した手法である.SVM と同様にカーネルトリックを 用いることによって非線型なモデリングを行なうことが可能 となっている，SVR 法においては，下記の值を最小化するよ うに学習が行なわれる。

$$
\frac{1}{2}\|\mathbf{b}\|^{2}+C \sum_{i}\left|y_{i}-f\left(\mathbf{x}_{i}\right)\right|_{e}
$$

ただし，

$$
\begin{aligned}
& f\left(\mathbf{x}_{i}\right)=\phi\left(\mathbf{x}_{i}\right) \mathbf{b}+v \\
& \left|y_{i}-f\left(\mathbf{x}_{i}\right)\right|_{e}=\max \left(0,\left|y_{i}-f\left(\mathbf{x}_{i}\right)\right|-e\right)
\end{aligned}
$$

である。ここで $y_{i}$ および $\mathbf{x}_{i} \in R^{1 \times n}$ は $i$ 番目のモデル構築 用デー夕， $\phi$ はある非線型関数, $\mathbf{b}$ は回帰係数ベクトル, $v$ は 定数項, $e$ は誤差の閾值である. (B. 1) 式を最小化すること により，モデル構築用データへの適応性と汎化能力のバラン スのとれた非線型モデルが得られる．(B. 1) 式の $C$ は, 二つ の項の間で重み付けを調整するための係数であり, 学習デー 夕の特徴に応じて最適化を行なう必要がある.

新しいデータ $\mathbf{x}_{j} \in R^{1 \times n}$ の予測值は以下のように表わさ れる。

$$
f\left(\mathbf{x}_{i}\right)=\sum_{i=1}^{m}\left(\alpha_{i}-\beta_{i}\right) K\left(\mathbf{x}_{i}, \mathbf{x}_{j}\right)+v
$$

ここで $\alpha_{i}, \beta_{i}$ は (B. 1) 式の最小化によって得られるパラメー 夕, $K$ はカーネル関数である. カーネル関数としては, 以下 に示すガウシアンカーネルを使用した.

$$
\begin{aligned}
K\left(\mathbf{x}_{i}, \mathbf{x}_{j}\right) & =\phi\left(\mathbf{x}_{i}\right) \phi\left(\mathbf{x}_{j}\right)^{T} \\
& =\exp \left(-\gamma\left\|\mathbf{x}_{i}-\mathbf{x}_{j}\right\|^{2}\right)
\end{aligned}
$$

カーネル関数中の $\gamma$ についても, 適用するデータに応じた最 適化が必要である。なお今回は, $e$ を指定する代わりに $e$ を 超える誤差をもつデータの割合に対する上限 $\nu$ を指定する $\nu$-SVR 法 ${ }^{8)}$ を用いた.

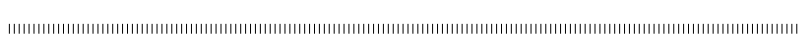

\section{[著 者 紹 介]}

金子弘昌 (正会員)

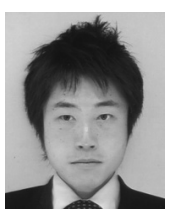

2011 年東京大学大学院工学系研究科化学システ 厶工学専攻博士課程修了. 同年東京大学大学院化 学システム工学専攻助教, 現在に至る. 推定制御, プロセス管理, ケモメトリックス, 膜分離活性污 泥法などに関する研究などに従事 (工学博士).

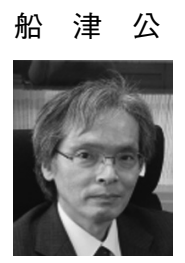

1983 年九州大学大学院理学研究科化学専攻博 士課程修了. 84 年豊橋技術科学大学物質工学系助 手, 92 年同上知識情報工学系助教授, 2004 年東京 大学大学院工学系研究科化学システム工学専攻教 授，現在に至る。ケモインフォマティックス，分 子設計, 材料設計, 反応設計, 推定制御, プロセ ス管理などに関する研究などに従事. (理学博士).

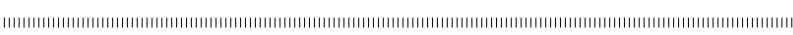

